\title{
O ENSINO DA LITERATURA E SUA RELAÇÃO COM A FORMAÇÃO DE LEITORES EM SALA DE AULA
}

\author{
Rachel Fátima dos Santos NUNES \\ (Universidade do Estado do Rio de Janeiro) \\ rachelsnunes@ig.com.br
}

\begin{abstract}
Resumo: Discute-se aqui o papel da literatura em sala de aula, considerando o processo de escolarização da leitura literária. $\mathrm{Na}$ escola, as abordagens do texto literário geralmente não se apresentam diversificadas, contribuindo para que o educando desenvolva uma compreensão mitificada e homogênea da literatura clássica. Este artigo objetiva ampliar as reflexões sobre leitura, literatura e escola, problematizando de que modo é possível desenvolver aulas dinâmicas de literatura, contribuindo para estreitar relações entre o texto literário e o leitor.
\end{abstract}

Palavras-chave: Escolarização. Leitura. Literatura e escola. Texto literário. Sala de aula.

\section{TEACHING LITERATURE AND ITS RELATION WITH THE EDUCATION OF READERS IN THE CLASSROOM}

\begin{abstract}
This paper discusses the tension involving the role of literature in the classroom, considering the educational process of reading literature. At school, approaches to the literary text in general are not diversified, which forces the students to develop a mythologized and uniform understanding of classical literature. Therefore, this article aims to expand the reflections on reading, literature and school, as well as discuss how the teacher can plan dynamic literature classes, and how they can contribute to strengthening relations between the literary text and the reader.
\end{abstract}

Keywords: Schooling. Reading. Literature at school. Literary text. Classroom. 


\section{Introdução}

A literatura pode muito. Ela pode nos estender a mão quando estamos profundamente deprimidos, nos tornar ainda mais próximos dos outros seres humanos que nos cercam, nos fazer compreender melhor o mundo e nos ajudar a viver (TODOROV, 2010, p.76).

Os problemas e as dificuldades referentes à formação de leitores literários têm sido objeto de muitas pesquisas e debates nos últimos tempos. Multiplicamse os estudos voltados para as questões de ensino, de leitura e de literatura. Verificam-se, com isso, alguns sinais de resistência dos jovens à leitura dos clássicos: consideram os textos difíceis, com vocabulário inacessível, além de apresentarem ritmo lento e temas desinteressantes.

Mas o que os jovens estão lendo atualmente? Pesquisas que buscam elencar as preferências dos jovens leitores de hoje chegam a resultados semelhantes: uma aversão pelos livros clássicos, e preferência por leituras variadas da internet, revistas e jornais. Quando são questionados a respeito da leitura literária, as obras citadas são "Harry Potter" (J. K. Rowling), "Senhor dos Anéis" (J. R. R. Tolkien), "O turno da noite" (André Vianco) e, mais recentemente, a série "Crepúsculo" (Stephenie Meyer) - citando os mais populares. Estes, no entanto, são considerados exemplares da literatura de massa, mais conhecidos no meio acadêmico como produtos de gosto duvidoso, de baixa qualidade literária.

Esta literatura de massa deveria ser desprezada pelas escolas ou poderia servir como um caminho a ser percorrido para alcançar um objetivo maior, que seria a literatura clássica? O fato é que, por ser considerada de qualidade inferior, na maioria das vezes, a literatura de massa é sistematicamente banida dos currículos escolares.

Maria Cristina Weitzel Tavela (2010), ao discutir a formação do leitor literário, cita Muniz Sodré (1988), e lembra que há dois tipos de literatura: a culta e a de massa. Para Sodré, lembra a autora, a literatura de massa não utiliza de forma medíocre o discurso literário, mas é a manifestação de um discurso específico.

Se, para ser considerada culta, a literatura deve passar pelo reconhecimento das academias, a literatura de massa não tem este suporte. Sua produção e seu consumo partem do jogo da oferta e da procura, ou seja, do mercado consumidor: 
"A diferença das regras de produção e consumo faz com que cada uma dessas literaturas gere efeitos ideológicos diferentes" (SODRÉ, 1988, p.6 apud TAVELA, 2010, p.4). E Tavela continua argumentando com Sodré, afirmando que, na literatura de massa, "o que importa mesmo são os conteúdos fabulativos, destinados a mobilizar a consciência do leitor, exasperando a sua sensibilidade. É o mercado, e não a escola, que preside as condições de produção do texto" (TAVELA, 2010, p.4).

Sodré (2008) lembra que uma das instâncias que viabilizam e justificam os estudos da literatura de massa se refere aos folhetins dos séculos anteriores. A cada dia um novo capítulo das histórias contadas nos jornais de grande circulação era publicado, o que fazia com que o leitor comprasse o próximo exemplar do jornal. Assim, pode-se afirmar que, de certa forma, a literatura apresenta relação com o jornalismo diário.

Assim, "o texto de massa mantém visível a sua estrutura através de personagens fortemente caracterizadas, de uma abundância de diálogos (capazes de permitir uma adesão mais intensa do leitor à trama) e de uma exploração sistemática da curiosidade do público" (SODRÉ, 1988, p.17 apud TAVELA, 2010, p.04).

Retomando o tema do presente artigo, cabe indagar como os alunos estão sendo apresentados à leitura, em especial à leitura literária? Os livros trabalhados pela escola chamam a atenção dos estudantes e despertam neles o prazer da leitura? Na escolha, o gosto dos alunos é levado em consideração? Como está sendo aproveitado o poder da literatura?

\section{1 - A sala de aula e o texto literário}

Verifica-se que boa parte dos alunos, em geral leitores iniciantes, rejeita os livros indicados pela escola, principalmente os clássicos da literatura universal, por considerarem textos difíceis de ler cujos conteúdos estão muito distantes da sua realidade. As aulas que deveriam servir para aproximar esses alunos da obra literária, geralmente têm seu enfoque na explanação de nomes e obras consagradas. Como resultado, tem-se o efeito inverso: o que deveria aproximar os jovens da literatura acaba por afastá-los. Imaginemos um jovem aluno, do subúrbio carioca, tentando entender o que se passa na cabeça da personagem 
Heathcliff do romance $O$ morro dos ventos uivantes, de Emily Brontë. Sem identificação não há sedução; sem sedução, não se dá a interação que vai fazer desse jovem aluno um leitor, ou seja, um bom leitor.

No que se refere a obras e textos trabalhados em sala de aula, é necessário que seja dada voz ao aluno. Sendo o cânone literário (BLOOM, 1994) a âncora do trabalho de literatura na escola, além de ser respaldada por textos clássicos de ótima qualidade, sua apresentação deve ser reservada ao alunoleitor mais maduro. No entanto, o trabalho com a literatura de massa pode ser benéfico, visto que alguns estudiosos da literatura já reconhecem que os Bestsellers são poderosos propagadores de leitura.

O próprio Todorov (2009) afirma:

Estou convencido de que, para aceder à grande literatura, deve-se primeiro aprender a amar a leitura (...). Eu mesmo, há muito tempo, comecei a ler versões simplificadas dos clássicos em búlgaro (...). Isso não me impediu de abordar o texto completo do romance alguns anos mais tarde. Nesse ponto de vista, eu recomendo sempre "O Conde Monte Cristo", de Alexandre Dumas, ou, por que não, as Aventuras de Harry Potter?

Além dos desafios da literatura de massa em sala de aula, o avanço das tecnologias com ênfase na internet trouxe desafios para serem enfrentados pelos educadores contemporâneos, tanto com seu uso em sala de aula quanto às formas de uso linguístico por parte do aluno que, por se identificar com os meios, acaba sofrendo interferência na sua escrita.

As mudanças da escrita na era digital ${ }^{1}$ - refletidas sob o impacto do avanço tecnológico na identidade do sujeito e na instituição escolar, deram origem aos gêneros digitais que se configuram como novas formas de utilização da escrita no espaço hipermidiático, como o hipertexto. Este, produzido coletivamente pelos usuários da internet, modifica a relação leitor-escritor. Hoje é possível ler livros

\footnotetext{
${ }^{1}$ A Bienal do Livro de São Paulo de 2008 realizou o projeto Livro de Todos (IMESP, 2008 ISBN 9788570606129) como parte da campanha publicitária da vigésima edição do evento: um livro colaborativo, a fim de contribuir para a democratização do livro e da literatura no Brasil. O projeto consistiu em uma obra coletiva através da Internet em que o participante, após ler a história já escrita, pôde continuar a escrevê-la dando o caminho que quisesse à história. Com o primeiro capítulo de autoria do renomado escritor e membro da Academia Brasileira de Letras Moacyr Scliar, o livro foi publicado pela Imprensa Oficial do Estado de São Paulo, com 18 capítulos, e foi lançado na 20a Bienal do Livro de São Paulo, com capa ilustrada por Maurício de Sousa. A seleção dos textos dos internautas e a edição do livro coube ao jornalista Almyr Gajardoni, que teve de integrar os diferentes estilos de texto dos 173 autores numa obra única. $O$ site do projeto recebeu 362 textos para o livro e foi acessado por 14.238 internautas. FONTE: <http://pt.wikipedia.org/wiki/Livro_de_Todos>
} 
que foram escritos por vários autores, cada um escrevendo uma parte da história, todos desconhecidos entre si, como o exemplo citado na nota 1.

Sérgio Roberto Costa, citando Marcuschi, diz que:

[...] a fronteira entre leitor e escritor torna-se imprecisa, pois o leitor-navegador não é um mero consumidor passivo, mas um produtor do texto que está lendo, um coautor ativo, leitor capaz de ligar os diferentes materiais disponíveis, escolhendo seu próprio itinerário de navegação, que também pode trazer seus problemas, pela sobrecarga exigida, a que Marcuschi (1999), chama de estresse cognitivo (COSTA, 2009, p.47-48).

Para Marcuschi (1999), o hipertexto é algo totalmente inovador; porém, a novidade se efetiva pela tecnologia, que proporciona a integração dos elementos (notas, citações, referências) que aparecem no texto impresso, subvertendo os movimentos e redefinindo a função dos constituintes textuais clássicos. $\mathrm{Na}$ visão do autor, trata-se de um processo realizado num novo espaço - o ciberespaço, de leitura/escritura multilinearizado, multissequencial e não determinado. Hoje, a propaganda é o segmento que mais utiliza esses recursos, fazendo de suas peças verdadeiras obras de arte.

O avanço tecnológico e a globalização, na contemporaneidade, não apenas romperam as fronteiras espaciotemporais, como também produziram o desgaste da distinção entre alta cultura e cultura de massa, algo que está explícito na nova forma de escrever e de se comunicar, através de Chats, MSN, SMS, E-mail e outros.

Vive-se hoje na chamada sociedade da informação, em um espaço em que a comunicação, mediada pelo computador (ou suas variantes), e as questões de linguagem assumem um papel fundamental na vida pós-moderna, ou como denomina Pierre Lévy (1999), na cibercultura. Nossa Era, marcada pelo advento de novas formas midiáticas (computador coletivo, internet), acabou por transformar o tempo (agora visto como simultaneidade) e o espaço (universo de informações navegáveis de forma instantânea e reversível), proporcionando ainda uma mudança no suporte da leitura e da escrita.

Ao interagirem, os adolescentes efetivam práticas de leitura e de escrita diferentes dos processos tradicionais de letramento e alfabetização. Eles agora lidam com formas gráficas e imagens digitais e em 3D. Com isso, não mais consideram as normas gramaticais na escrita, mas a reconfiguram, 
ressignificando-a, com o uso de barras, parênteses, traços e outros sinais que formam feições humanas (emoticons) e passam a representar, como mensagens cifradas, inclusive estados da própria subjetividade.

O papel da escola, portanto, é o de receber e de trabalhar o uso dos meios de comunicação de casa até a sala de aula. Assim, os alunos, utilizando os mais variados recursos, principalmente aqueles que conhecem e que lhes dão prazer, poderão encontrar satisfação de aprender. Se a escola nega essa integração entre suas práticas e a realidade do aluno, o distanciamento já existente entre o mundo interno e externo tenderá sempre a aumentar. É por isso que escola precisa se aparelhar e se modernizar para cumprir seu papel formador.

Retomando a questão da literatura de massa, que acompanha em formato e conteúdo os modelos contemporâneos, chega-se à conclusão de que essas obras podem exercer mais sedução nos jovens alunos, despertando neles o prazer da leitura. Dessa forma, tanto a literatura de massa que, sendo a estimuladora inicial do gosto pelo texto, leva ao hábito de leitura, como os gêneros digitais, com seus recursos visuais e interativos, podem ser ferramentas educacionais para 0 processo de ensino-aprendizagem em sala de aula.

\section{2 - O ensino da literatura}

A literatura não nasce no vazio, mas no centro de um conjunto de discursos vivos, compartilhando com eles numerosas características. (TODOROV, 2010, p. 22)

Sabemos que a escola reproduz em suas práticas até mesmo os vícios e equívocos praticados pelos governos. Portanto, ainda hoje é possível perceber na dinâmica da escola, principalmente da escola pública, um movimento que perpetua o maniqueísmo apontado por Machado de Assis $^{2}$, em um texto escrito ainda no tempo do governo imperial. Literatura e nacionalismo andaram de mãos dadas no Brasil, mas a parceria já despertou crítica dos estudiosos do tema.

O que se tem em sociedade hoje nas classes populares é, via de regra, uma juventude mediana, despreparada, porque não leitora, oriunda de uma escola

\footnotetext{
2 Machado de Assis, ao fazer a revisão histórica do nacionalismo [na literatura brasileira] em "Instinto de Nacionalidade" (1873), questionou a radicalização maniqueísta no tratamento da questão nacional. Machado denuncia nesse texto alguns equívocos do nacionalismo: o exclusivismo da temática indianista, o excessivo apego à descrição da natureza e dos costumes brasileiros.
} 
básica que não dá conta de avançar o nível de escolarização geral. Certamente, isto ainda reverbera a escola arcaica e descuidada, em todos os sentidos, dos inícios da formação de nossa sociedade. Esse hiato entre a escola e a realidade social - em termos de leitura e letramento - é um fosso que se aprofunda a cada década.

Quanto às novas tecnologias digitais, podemos arriscar que a própria internet não produz qualquer ruptura na produção literária. Beatriz Sarlo, professora de literatura e autora contemporânea, não vê inovação na produção literária em função das novas tecnologias. Para ela, um autor pode escrever o mesmo romance tanto com lápis e papel como no Office Word, pois o meio, em si, não o obriga a percorrer caminhos novos. O livro impresso é uma tecnologia muito sofisticada, e que não está, ainda, ameaçado de obsolescência por conta da internet. Sarlo (2013) admite que, diante das novas mudanças trazidas pelas novas tecnologias midiáticas, é preciso lidar com um conceito ampliado de literário.

Diante de tal constatação, o que se pode propor é que o uso das tecnologias na sala de aula deva ser um "processo de aglutinação", como propunha Oswald de Andrade ${ }^{3}$ que, em seu manifesto antropofágico, propunha juntar o que se tem com o novo que chega. O que falta na sala de aula, hoje, é essa noção de aproveitamento de acervo. Portanto, usar a literatura de massa nos programas de leitura e suscitar reflexão no jovem aluno sobre aquilo que ele lê (mesmo que seja a aventura do Harry Potter, acerca de um reino encantado, com seres mágicos no enredo), poderá convidá-lo a se colocar no centro da trama romanesca, e tirar dela o prazer de fantasiar... Cremos que esta deve ser a tarefa da sala de aula, nas aulas de formação de leitores.

\section{Considerações finais}

O histórico de nossa formação literária, desde o Séc. XVII, parece confirmar a crítica machadiana. Começamos com uma literatura nos moldes europeus, mas que trazem em seu conteúdo os questionamentos nacionais. $\mathrm{O}$

\footnotetext{
${ }^{3}$ José Oswald de Sousa Andrade, dito Oswald de Andrade, foi um dos promotores da "Semana de Arte Moderna" (São Paulo, 1922), tornando-se um dos grandes nomes do modernismo literário brasileiro. Autor, dentre outros, do famoso “Manifesto Antropófago" (1928).
} 
excesso de zelo do nacionalismo literário passou por várias etapas, até aportarmos na literatura contemporânea, com uma mistura de literatura bemcomportada - que busca aproximações aos clássicos; uma produção de autores das periferias - de conteúdo realista e violento; e uma produção pós-moderna de autores que pretendem ser traduzidos e publicados fora do país.

O Brasil tem um painel de bons autores contemporâneos, que tratam de assuntos afins à nossa cultura e à nossa realidade. Portanto, não se pode fugir dessa discussão, e dizer que o brasileiro não lê e que o jovem não gosta de livros. Nunca na história desse país se publicou tanto. Livrarias estão sendo inauguradas e os sebos nunca venderam tantos livros usados como ocorre atualmente. $O$ advento da internet foi crucial para o incremento da divulgação do livro, e consequentemente do processo de compra e venda. Pelo óbvio: se estão sendo comprados, os livros estão sendo lidos.

Como estudiosa da literatura contemporânea brasileira, vejo a necessidade de levar à sala de aula, não apenas as aventuras de Harry Potter e do Conde de Monte Cristo, mas também obras que tratem das problemáticas que nos dizem respeito mais de perto. Ainda que as obras clássicas sejam suficientes para acessar o subjetivo e o inconsciente, enquanto o leitor não for capaz de processar um subtexto durante sua atividade leitora - o que ele fará de modo mais natural com um texto cujo tema esteja mais próximo de sua realidade - ele não alcançará ler com prazer uma obra literária, qualquer que seja ela. A escola deve cuidar dessa questão com a máxima urgência.

\section{Referências bibliográficas}

BLOOM, Harold. O cânone ocidental. Trad. Marcos Santarrita. 2.ed. Rio de Janeiro: Objetiva, 1994.

COIMBRA, Rosicley Andrade. Por que a literatura [está] em perigo? Resenha de A literatura em perigo, de Tzvetan Todorov. Darandina, v.3, no 1 (UFJF), nov., 2010.

COSTA, Sérgio R. Leitura e escritura de hipertextos: implicações didáticopedagógicas e curriculares. Veredas. Revista de estudos linguísticos, v.4, no 1, Juiz de Fora: EDUFJF, jan./jun., 2000, p.43-49.

LEVY, Pierre. Cibercultura. (Tradução de Carlos Irineu da Costa). Rio de Janeiro: Editora 34, 1999. 
MACHADO DE ASSIS, Joaquim Maria. Instinto de Nacionalidade. Novo Mundo, 1873. Obra de domínio público, disponível em

<http://www.olivro.com/machado/literatura/ index.html\#Instinto>

MAFRA, Nubio. A literatura de massa como iniciação à leitura. Revista Vydia da UNIFRA, janeiro/junho de 2001.

MARCUSCHI, Luiz Antônio. O hipertexto como novo espaço de escrita em sala de aula. Linguagem e Ensino, v. 4, no1, 2001, p.79-111.

MARCUSCHI, Luiz Antônio. Cognição, Linguagem e Práticas Interacionais. Rio de Janeiro: Lucerna, 2007.

SARLO, Beatriz. Cenas da vida pós-moderna - intelectuais, arte e videocultura na Argentina. (Tradução de Sergio Alcides). Rio de Janeiro: UFRJ, 2013.

SODRÉ, Muniz. Best-Sellers: a literatura de mercado. São Paulo: Ática, 2008.

TAVELA, Maria Cristina Weitzel. Literatura de massa na formação do leitor literário. Darandina, v.3, oㅡ 1 (UFJF), nov., 2010. ISSN: 1983:8379.

TODOROV, Tzvetan. A Literatura em perigo. Trad. Caio Meira). 3.ed. Rio de Janeiro: DIFEL, 2010. 
Artigo recebido em: 04 de março de 2015

Artigo aprovado em: 06 de abril de 2015

Sobre a autora:

Rachel Fátima dos Santos Nunes é coordenadora do Curso de Letras, e professora de graduação e pós-graduação nas áreas de Literatura Brasileira e Teoria Literária, da Universidade Estácio de Sá; também é professora da UNICARIOCA, nos cursos de Jornalismo e Pedagogia. Foi ainda substituta em Literatura Brasileira na Universidade do Estado do Rio de Janeiro - UERJ. 